The effect of an electromagnetic body force on an electrically conducting fluid permits a range of problems widely exploited by both theoreticians and experimental workers, but it is disturbing to note that, although the first words in this journal assert its existence to publish experimental and theoretical research papers, none of the eleven papers in the first issue is experimental. One contribution considers ambipolar diffusion in a semiconductor in the presence of a magnetic field and the remainder deal with aspects of wave propagation.

It will require the publication of three or four issues before the general pattern emerges, but I would plead with the editors, a mathematician, an astronomer, a theoretical physicist and an aeronautical engineer, to strike a healthier balance between theory and experiment in the future.

In its present form, as a journal of plasma physics, it has a limited appeal. JoHN PAIN

\section{TABLES BY COMPUTER}

\section{$X-R a y$ Diffraction Tables}

By J. H. Fang and Donald F. Bloss. (Carbondale and Edwardsville: Southern Illinois University Press; London and Amsterdam: Feffer and Simons, Inc., 1966.) \$12.75; $898.3 d$.

Fourteen years ago Philips Technical Library brought out the Charts for Solution of Bragg's Equation, compiled by Parrish and Irwin, which rapidly gained a place beside every diffractometer. Now the computer age provides us with tables rather than graphs, bulkier but directly readable to more decimal places. Each page of the tables by Fang and Bloss covers 50 hundredths of a degree $2 \theta$, in the range $0.11^{\circ}$ to $180^{\circ}$, with columns giving corresponding interplanar spacings, to five figures, for diffraction of the $\alpha_{1}, \alpha_{2}, \bar{\alpha}$ (weighted mean of $\alpha_{1}$ and $\alpha_{2}$ ) and $\beta$ components of the $K$ radiations of copper, iron, molybdenum, and chromium, and of $W L \alpha_{1}$ radiation; $\sin ^{2} \theta$ is also given to five figures. The source of the wavelength data is not stated, but the $K \alpha$ values are those of the International Tables for Crystallography, 1962. Stopwatch timings show little difference between the Philips charts and the new tables when looking up Bragg angles of known interplanar spacings, but for finding interplanar spacings, given the Bragg angle, the new tables are about twice as fast as the charts and are pleasant and easy to use. It was especially for the latter operation that the tables were designed; for such use they can be recommended, and should become popular. A. R. LANG

\section{ELECTRONICS REFRESHER COURSE}

\section{Basic Electronics for Scientists}

By James J. Brophy. Pp. xiii + 471. (New York: MeGrawHill Book Company, Inc.; Maidenhead: McGraw-Hill Publishing Company, Ltd., 1966.) $76 s$.

This is an excellent book. Its contents cover circuit theory, the physies of electronic devices and the use of both these in electronic systems. This is in itself welcome, for while there are many books that cover one or two of these topics together there are very few that treat all three together and as well as this one.

The circuit theory includes Thevenin and Norton equivalent circuits, complex impedance methods and simple filters, tuned circuits and transient phenomena. It is done at the level of a first course and avoids the mathematical elaboration of general circuit theory.

A good attempt is made to present briefly and simply the physics of semiconductors so that the workings of the junction diode and transistor can be understood without a previous course in solid state physics. Zener and tunnel diodes, field effect transistors, integrated circuits and other recent developments are touched upon. Thermionic devices are not neglected.

Solid state and valve amplifiers and oscillators are described. The discussion of digital and pulse techniques includes an introduction to digital logic and computers. The various types of feed-back are covered, including operational feed-back and its use in control and analogue computers. There is a welcome emphasis on instrumentation which includes electrometers, phase sensitive detection, various transducers and recorders, counters and timers.

All these matters are clearly described. Little background in mathematics, electromagnetism or solid state physics is required, yet the reader becomes acquainted with the way electronics is currently used in research and instrumentation. This book can be recommended not only to students (each chapter has a set of problems with numerical answers) but also to those more mature who may wish to be refreshed or brought up to date.

E. G. Wilson

\section{MAKING FILMS}

\section{Physics of Thin Films}

Advances in Research and Development, Vol. 3. Edited by Georg Hass and Rudolf $\mathrm{E}$. Thun. Pp. xiii +318 . (New York: Academic Press, Inc.; London: Academic Press, Inc. (London), Ltd., 1966.) $112 s$.

THe third volume of this useful series is devoted largely to matters concerned with the techniques of preparation of films. This is a timely volume. Over the last two decades, a considerable body of expertise has grown up in this field. It has not hitherto been possible to find, in a single volume, a thorough discussion of the really basic laboratory problems involved in thickness-and ratemeasurement, cathode sputtering, gas-phase deposition and in activation and recrystallization of II-VI semiconductor films.

Although in the realm of film monitoring there have been no radically new methods in recent years, many existing methods have been refined and translated from the laboratory lash-up to the stage of commercial hardware. A useful summary of the present state enables immediate assessment of the available methods. The art of sputtering (for art it surely is) is in the throes of making a come-back after temporary eclipse by the "better understood" method of thermal evaporation. Illusions are probably shared equally between the two methods. The techniques and applications of cathode sputtering are usefully summarized in this volume.

The radically different process of film-making by pyrolytic decomposition or by surface polymer formation has excited interest in recent years, giving promise of stable, hole-free films in conditions where previous methods failed. A bird's-eye view of the present situation is given. The latter type of film is likely to play a significant part in the development of microelectronics, as is also the II-VI semiconductor film, for which the technology and properties are fully discussed.

The study of the mechanical properties of films, notwithstanding their importance for technological applications, has given rise to many headaches, partly because of the experimental difficulty and the consequent variation in the results of different observers. The article by Hoffman gives a useful summary of the present state, bringing out clearly how great is the need for more definitive experiments.

The activities of the near-infra-red region of the spectrum depend heavily on the lead salt photoconductors used for detection. Although probably most of us are 